\title{
Rectal prolapse in children: a study of 71 cases
}

\author{
Mohammad-Hossein Sarmast ${ }^{1}$, Shahnam Askarpour ${ }^{1}$, Mehran Peyvasteh ${ }^{1}$, Hazhir Javaherizadeh ${ }^{2}$, \\ Meisam Mooghehi-Nezhad ${ }^{1}$
}

1Department of Surgery, Imam Khomeini Hospital, Ahvaz Jundishapur University of Medical Sciences, Ahvaz, Iran

2Department of Paediatrics, Abouzar Children's Hospital, Ahvaz Jundishapur University of Medical Sciences, Ahvaz, Iran

Prz Gastroenterol 2015; 10 (2): 105-107

DOI: $10.5114 /$ pg.2015.49003

Key words: rectal prolapse, anus, rectum, children.

Address for correspondence: Prof. Shahnam Askarpour MD, Ahvaz Jundishapur University of Medical Sciences, Imam Khomeini Hospital Azadegan St, Ahvaz, 6135873391 Ahvaz, Iran, phone: 98-611-2221102, e-mail: shahnam_askarpour@yahoo.com

\begin{abstract}
Introduction: Prolapse of the rectum is the herniation of the rectum through the anus, which may be categorised as mucosal or complete.

Aim: To evaluate the clinical manifestation, treatment, and surgical complications of children with rectal prolapse over a 6-year period.

Material and methods: This study was carried out on children aged $<14$ years who were admitted or referred for rectal prolapse that failed to respond after medical treatment in Imam Khomeini and Abouzar Children's Hospital. Duration of the study was 6 years starting in March 2002. These cases were referred after failure of medical and conservative treatment. Age, sex, clinical manifestation, and type of procedure were recorded. Analysis was done using SPSS version 11.0 (SPSS Inc, Chicago, IL, USA). The $\chi^{2}$ test was used for comparison.

Results: Seventy-one cases were included in this study. Of these cases, 50 (70.4\%) were male and 21 (29.6\%) were female $(p<0.0001)$. Mean age of cases was $4.97 \pm 3.42$ years (range: 2 days to 13 years). Of the male cases, $38 \%$ were in the age range of 3-6 years. In female cases, $57.1 \%$ were in the range of $1.5-3$ years. Of all 71 cases, injection sclerotherapy was done for $50(70.43 \%)$ for the first time. Twenty-one cases had history of injection sclerotherapy and $16(22.53 \%)$ were treated by perineal surgery, and 5 (7.04\%) had abdominal surgery. One case experienced recurrent rectal prolapse (1.40\%) following injection sclerotherapy.

Conclusions: In girls, more than half of the cases were in the age range 1.5-3 years. Among male cases, 38\% were in the age range of 1.5-3 years. The results of treatment of rectal prolapse in our hospitals was similar to that seen in developed countries.
\end{abstract}

\section{Introduction}

Prolapse of the rectum is the herniation of the rectum through the anus, which may be categorised as mucosal or complete [1]. The mucosal type of rectal prolapse is the least serious form and is the most common type in the paediatric population [2]. Diagnosis of rectal prolapse requires physical examination and obtaining thorough history. However, diagnosis may be difficult especially in the paediatric population [3]. Most children with rectal prolapse do not require specific treatment. Treatment of constipation, treatment of parasitic infection, and avoiding excessive strain are appropriate measures for the treatment of uncomplicated rectal prolapse. Surgical procedures may be required for cases who failed to respond to medical methods [4]. Injection sclerotherapy is the first surgical method used for the treatment of cases who failed to respond to medical treatment. Children with recurrences after injection sclerotherapy may be candidates for surgical treatment [5]. Although there are several types of surgical procedures for the treatment of refractory rectal prolapse, few of them were used for treatment in a single institution [6].

\section{Aim}

The aim of this study was to evaluate the frequency of surgical complications of rectal prolapse among children over a 6-year period. 


\section{Material and methods}

This study was carried out on children aged $<14$ years, who were admitted or referred for surgery in Imam Khomeini and Abuzar Children's Hospital of Ahvaz-Iran. All patients referred for surgery after completed workup and failure of medical and conservative treatment for rectal prolapse. The duration of the study was 6 years starting on March 20, 2002.

\section{Statistical analysis}

Analysis was done using SPSS version 11.0 (SPSS Inc, Chicago, IL, USA). The $\chi^{2}$ test was used for comparison.

\section{Results}

Seventy-one cases were included in this study. Of all cases, 50 (70.4\%) were male and 21 (29.6\%) were female $(p<0.0001)$. Mean age of cases was $4.97 \pm 3.42$ years (range: 2 days to 13 years). The age distribution is shown in Table I. The clinical manifestations are shown in Table II. The methods used for surgery are shown in Table III. The recurrence rate was $1.4 \%$ (1 case). Of all

Table I. Age distribution among cases

\begin{tabular}{cccc} 
Age [years] & Male, $n(\%)$ & Female, $n(\%)$ & Total, $n(\%)$ \\
\hline$<1.5$ & $6(66.67)$ & $3(33.33)$ & $9(100)$ \\
\hline $1.5-<3$ & $9(42.86)$ & $12(57.14)$ & $21(100)$ \\
\hline $3-<6$ & $19(86.36)$ & $3(13.64)$ & $22(100)$ \\
\hline $6-<9$ & $5(71.42)$ & $2(28.58)$ & $7(100)$ \\
\hline $9-<13$ & $11(91.66)$ & $1(8.34)$ & $12(100)$ \\
\hline Total & $50(70.42)$ & $21(29.58)$ & $71(100)$
\end{tabular}

Table II. Clinical manifestations of cases

\begin{tabular}{lc} 
Manifestation & Result, $\boldsymbol{n}$ (\%) \\
\hline Rectal prolapse & $10(14.1)$ \\
\hline Exteriorization mass from the rectum & $49(69)$ \\
\hline Diarrhoea & $17(23.9)$ \\
\hline Constipation & $6(8.5)$ \\
\hline Vomiting & $6(8.5)$ \\
\hline Bleeding after defecation & $26(36.6)$
\end{tabular}

Table III. Surgical methods used for treatment

\begin{tabular}{lc} 
Method & Result, $n(\%)$ \\
\hline Sclerotherapy & $50(70.43)$ \\
\hline Perineal surgery & $16(22.53)$ \\
\hline Abdominal surgery & $5(7.04)$ \\
\hline Total & $71(100)$
\end{tabular}

cases, 21 had history of recurrent rectal prolapse following injection sclerotherapy. These cases underwent surgical procedures.

\section{Discussion}

In the current study the mean age of the cases was 4.97 years (range: 2 days -13 years), and $31 \%$ of cases were in the range 3-6 years. In the Antao et al. study the mean age of the cases was 2.6 years (range: 4 months -10.6 years) [7]. In the UK, most rectal prolapses in children were seen before 2 years of age [8]. In Rwanda, the mean age of the cases was 4.3 years [8]. The mean age of our cases was similar to Rwanda and higher than in the study by Chaloner et al. [8] and the Antao et al. [7] study from the UK.

In our study (2002-2008), 60.6\% of cases had age 1.5 to 6 years. In the Sadighi et al. study from $1982-$ $2000,60 \%$ of cases had age range from 2 to 6 years [9]. This shows that the peak age in Iranian children remained constant for 26 years.

In the current study, $70.42 \%$ of cases were male and $29.58 \%$ were female. Our result was similar to that from the Bahador et al. study from Iran, with a male-tofemale ratio of $2.39 / 1$ [10]. In the study by Sadighi et al. from Tehran-Iran, of 67 cases with rectal prolapse, 50 (75\%) were male [9]. In the Antao et al. study, of 49 cases, 25 were male [7]. Another study reported equal distribution between boys and girls [11]. This difference between our results and those from other studies needs further research.

Prolapse of mass (96\%), bleeding after defecation (36.6\%), diarrhoea (23.9\%), prolapsed rectum (14.1\%), and constipation (6\%) were the most common signs and symptoms in our study. Rectal bleeding, pain with defecation, and incontinence were the most common symptoms in the study from Egypt [12]. Constipation was present in $8.5 \%$ of our cases. About $15-65 \%$ of cases with rectal prolapse have constipation [13]. The exact prevalence of constipation in our country is unclear, but it seems higher than in our study.

In our study, injection sclerotherapy was the most commonly used procedure. The recurrence rate was $1.40 \%$ in our study. In the Sadighi et al. study [9], sclerotherapy was used for $52 \%$ of cases, which is lower than in our study. Rahman et al. reported a 93.3\% response to injection sclerotherapy for their patients [14]. In the Antao et al. study, in 14-months follow-up the recurrence rate was zero [7]. In the study by Zganjer et al. on 86 children with rectal prolapse, $95.3 \%$ of patients showed a response to injection sclerotherapy [6].

The perineal approach had a lower operative mortality and morbidity than the abdominal approach [15, 16]. Due to the low sample size of cases who underwent 
abdominal approach, a conclusion was not possible in our study. In the study by Brown et al., 10\% of cases experienced recurrent prolapse [17]. Abdominal rectopexy is the method of choice for the treatment of rectal prolapse [18].

In this study we used saline as a sclerosant with more than 90\% success. Ethyl alcohol [10], D50W [19], $15 \%$ saline solution [20], and cow's milk [6] were used and reported to have efficacy of more than $90 \%$ by others. Our study and most of the other studies [7] showed that injection sclerotherapy is the most common effectively used procedure for treatment.

The main limitation of this study was the retrospective method.

\section{Conclusions}

The success rate of injection sclerotherapy in our hospital was similar to that seen in other studies. The average age of the cases was higher than in European studies. The male-to-female ratio in two studies from Iran were higher than reports from other countries. We recommend another study to clarify the high ratio of male-to-female in our country.

\section{Acknowledgments}

The cost of this thesis has been paid by the credit of approved research project no.u_86055 and all rights of this thesis is reserved for Ahvaz Jundishapur University of Medical Sciences.

\section{Conflict of interest}

The authors declare no conflict of interest.

\section{References}

1. Ibanez V, Gutierrez C, Garcia-Sala C, et al. The prolapse of the rectum. Treatment with fibrin adhesive. Cir Pediatr 1997; 10: 21-4.

2. Groff DB, Nagaraj HS. Rectal prolapse in infants and children. Am J Surg 1990; 160: 531-2.

3. Kuiper RJ, de Jong JR, Kneepkens CM. There is something coming out of the anus of my child. Ned Tijdschr Geneeskd 2011; 155: A2735.

4. Pikarsky AJ, Joo JS, Wexner SD, et al. Recurrent rectal prolapse: what is the next good option? Dis Colon Rectum 2000; 43: 1273-6.

5. Fahmy MA, Ezzelarab S. Outcome of submucosal injection of different sclerosing materials for rectal prolapse in children. Pediatr Surg Int 2004; 20: 353-6.

6. Zganjer M, Cizmic A, Cigit I, et al. Treatment of rectal prolapse in children with cow milk injection sclerotherapy: 30-year experience. World J Gastroenterol 2008; 14: 737-40.

7. Antao B, Bradley V, Roberts JP, et al. Management of rectal prolapse in children. Dis Colon Rectum 2005; 48: 1620-5.
8. Chaloner EJ, Duckett J, Lewin J. Paediatric rectal prolapse in Rwanda. J R Soc Med 1996; 89: 688-9.

9. Sadighi A, Pourang H, Askarpour S. Rectal prolpase in children: experience in 67 cases. Acta Medica Iranica 2003; 41: 277-9.

10. Bahador A, Foroutan HR, Hosseini SM, et al. Effect of submucosal alcohol injection on prolonged rectal prolapse in infants and children. J Indian Assoc Pediatr Surg 2008; 13: 11-3.

11. Safar B, Vernava AM 3rd. Abdominal approaches for rectal prolapse. Clin Colon Rectal Surg 2008; 21: 94-9.

12. Saleh AM. Rectal prolapse in children: rectopexy through posterior sagittal approach. Ann Pediatr Surg 2006; 2: 165-8.

13. Madiba TE, Baig MK, Wexner SD. Surgical management of rectal prolapse. Arch Surg 2005; 140: 63-73.

14. Rahman S, Hasanuzzaman A, Huda S. Management of rectal prolapse in children as a day care procedure. Journal of Dhaka Medical College 2010; 17: 116-20.

15. Whitlow CB, Beck DE, Opelka FG, et al. Perineal repair of rectal prolapse. J La State Med Soc 1997; 149: 22-6.

16. Hammond K, Beck DE, Margolin DA, et al. Rectal prolapse: a 10-year experience. Ochsner J 2007; 7: 24-32.

17. Brown AJ, Anderson JH, McKee RF, et al. Surgery for occult rectal prolapse. Colorectal Dis 2004; 6: 176-9.

18. Kościński T, Hermann J, Banasiewicz T. Management of recurrent rectal prolapse. Prz Gastroenterol 2013; 8: 243-6.

19. Chan WK, Kay SM, Laberge JM, et al. Injection sclerotherapy in the treatment of rectal prolapse in infants and children. J Pediatr Surg 1998; 33: 255-8.

20. Abes M, Sarihan H. Injection sclerotherapy of rectal prolapse in children with 15 percent saline solution. Eur J Pediatr Surg 2004; 14: 100-2.

Received: 6.03 .2014

Accepted: 23.10 .2014 